\title{
Numerical study of natural convection heat transfer from a heater placed in an enclosure with adjacent inclined sidewall
}

\author{
Ramiz, I. Al-Abushi, Lecturer \\ Department of Mechanical Engineering -University of Mosul - Iraq
}

\section{Abstract}

In this investigation, natural convection heat transfer from a heater placed on the bottom of a square enclosure with adjacent inclined wall was carried out . The inclined wall has a constant low temperature, while the heater element has a constant high temperature, and the remaining walls are insulated. The working fluid used is air with Prandtl number $(\operatorname{Pr}=0.72)$. The governing equations of the problem are solved numerically by using finite difference method. The numerical solution is presented for various Rayligh numbers, $\operatorname{Ra}\left(10^{3}-10^{5}\right)$, with different dimensionless parameters as length of heater $\left(Y_{h}\right)(0.1,0.3,0.5)$, different locations of the heater $\left(X_{h}\right)(0.25,0.5)$ and inclination angle of inclined cold wall $\Phi\left(10^{\circ}, 20^{\circ}, 30^{\circ}\right)$. The results are presented by isotherms and streamlines to show the behavior of the flow and temperature distribution - While the numerical results of heat transfer are presented by average Nusselt number and local Nusselt numbers at right, left and top sides of heater. The results show the effect of dimensionless parameters on heat transfer and Nusselt number. It is observed that the Nusselt number increased by increasing Raylig number, heater length , inclination angle of cold wall and where the heater is near the cold wall $\left(X_{h}=0.5\right)$.

Keywords : natural convection, heater, enclosure, heat transfer

$$
\begin{aligned}
& \text { دراسة عددية لانتقال الحرارة بالحمل الطبيعي من مسخن موضوع في حيز ذو جدار مائل }
\end{aligned}
$$

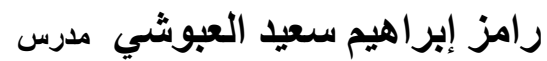

$$
\begin{aligned}
& \text { كلية الهندسة - قسم الهندسة الميكانيكية - جامعة الموصل } \\
& \text { الخلاصة }
\end{aligned}
$$

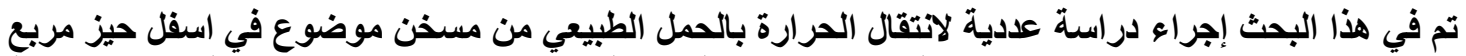

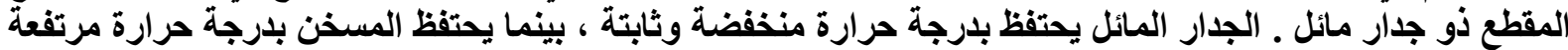

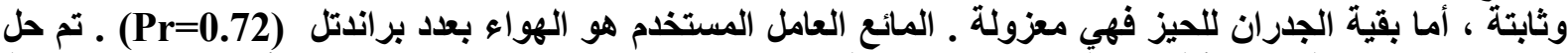

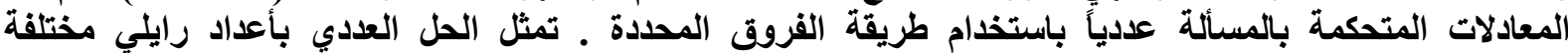

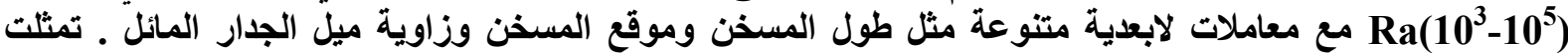

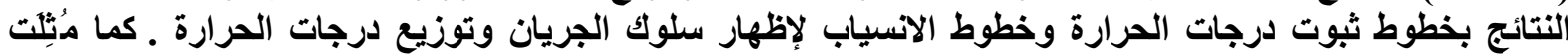

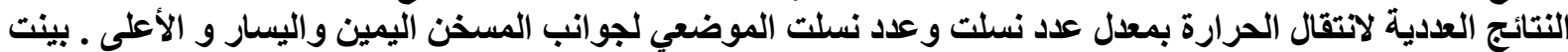

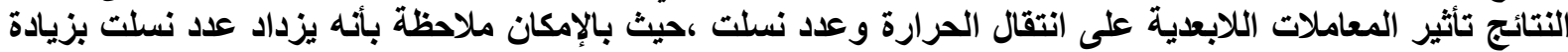

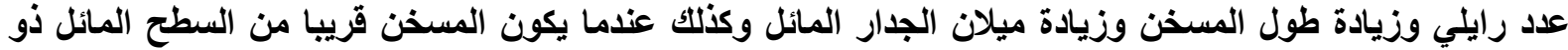

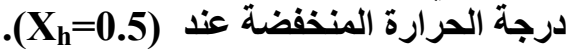
الكلمات المفتاحية : الحمل الطبيعي ، مسخن ، حيز ، المغل ، انتقال الحرارة 


\section{Nomenclature}

\begin{tabular}{|c|c|c|}
\hline Symbol & Definition & Dimensions \\
\hline $\mathrm{Cp}$ & Heat capacity at constant pressure & $\mathrm{J} / \mathrm{kgK}$ \\
\hline $\mathrm{K}$ & Thermal conductivity of fluid & $\mathrm{W} / \mathrm{mK}$ \\
\hline $\mathrm{L}$ & Lenth of the cavity & $\mathrm{M}$ \\
\hline $\mathrm{Nu}$ & Nusselt number & --- \\
\hline $\mathrm{P}$ & Fluid pressure & $\mathrm{N} / \mathrm{m}^{2}$ \\
\hline $\operatorname{Pr}$ & Prandtl numbers $=v / \alpha$ & $\begin{array}{ll}-- \\
\end{array}$ \\
\hline $\mathrm{Ra}$ & Rayleigh number & --- \\
\hline$t_{\mathrm{h}}$ & Thickness of heater & $\mathrm{M}$ \\
\hline $\mathrm{T}$ & Temperature & $\mathrm{K}$ \\
\hline $\mathrm{U}$ & Velocity in $\mathrm{x}$ direction & $\mathrm{m} / \mathrm{s}$ \\
\hline $\mathrm{V}$ & Velocity in y direction & $\mathrm{m} / \mathrm{s}$ \\
\hline $\mathrm{X}$ & Horizontal distance & $\mathrm{M}$ \\
\hline $\mathrm{X}_{\mathrm{h}}$ & Distance of heater location & $\mathrm{M}$ \\
\hline $\mathrm{X}_{\mathrm{h}}$ & Dimensionless heater location $=\mathrm{x}_{\mathrm{h}} / \mathrm{L}$ & --- \\
\hline $\mathrm{Y}$ & Vertical distance & \\
\hline $\mathrm{y}_{\mathrm{h}}$ & heater length & $\mathrm{M}$ \\
\hline $\mathrm{Y}_{\mathrm{h}}$ & Dimensionless heater length $=\mathrm{y}_{\mathrm{h}} / \mathrm{L}$ & \\
\hline$\psi$ & Stream function & $\mathrm{m}^{2} / \mathrm{s}$ \\
\hline$\omega$ & Vorticity & --- \\
\hline$\Omega$ & Dimensionless velocity $=\left(\omega \mathrm{L}^{2} \operatorname{Pr} / \mathrm{v}\right)$ & --- \\
\hline$\theta$ & Dimensionless temperature $=\left(T-T_{c}\right) /\left(T_{h}-T_{c}\right)$ & --- \\
\hline$\rho$ & Density & $\mathrm{Kg} / \mathrm{m}^{2}$ \\
\hline$v$ & Kinematic viscosity & $\mathrm{m}^{2} / \mathrm{s}$ \\
\hline$\phi$ & Angle of inclination of cold wall & \\
\hline$\alpha$ & Thermal diffusivity $=\mathrm{k} /(\rho \mathrm{Cp})$ & $\mathrm{m}^{2} / \mathrm{s}$ \\
\hline$\beta$ & Thermal expansion coefficient & $\mathrm{K}^{-1}$ \\
\hline$\hat{\psi}$ & Dimensionless stream function $=\psi \operatorname{Pr} / \nu$ & --- \\
\hline \multicolumn{3}{|c|}{ Subscript } \\
\hline $\mathrm{c}$ & Cold & \\
\hline $\mathrm{h}$ & Hot & \\
\hline
\end{tabular}

\section{Introduction:}

Study of natural convection heat transfer inside an enclosure has received a great deal of attention due to its implication in most engineering applications. These applications include solar collectors, cooling of micro-electric devices and nuclear reactors. Indeed, most of the researcher's works were concentrated on rectangular or square enclosures. So few studies were found on natural convection in non-rectangular enclosures. The medium inside these enclosures was porous or non-porous.

Natural convection in different geometrical enclosures has been extensively investigated. Some researchers investigated the effects of the geometric shapes on natural convection in enclosures such as triangle [1], parallelogram [2], trapezoidal [3], wavy [4] and so on. They showed that both flow and temperature fields are affected by the geometrical parameters. The 
partially heated sides can be used as a control parameter for heat transfer and fluid flow in enclosures. Many researchers studied the problem of divided rectangular or square nonporous enclosures with partition but a few researches deal with heaters or heated partition .

Varol , Oztop and Pop[5] performed numerical study of buoyancy-driven flow and heat transfer in an inclined trapezoidal enclosure filled with a fluid-saturated porous medium heated and cooled from inclined walls. The obtained results show that inclination angle is more influential on heat transfer and flow strength than that of the side wall inclination angle . It is also found that a Bénard regime occurs around $\varphi=90^{\circ}$, which depends on the inclination of the sidewall, Rayleigh number and aspect ratio.

Basak et al., [6] studied the natural convection in trapezoidal enclosures for uniformly heated bottom wall numerically. Parametric studies for the wide range of Rayleigh numbers Prandtl numbers, with various tilt angles of side walls. For linearly heated side walls, symmetry in flow pattern is observed. In addition, secondary circulations are observed near the bottom wall especially for larger Pr numbers. Average Nusselt number plots show higher heat transfer rates and the overall heat transfer rates at the bottom wall is larger for the linearly heated left wall and cooled right wall.

Sun and Pop [7] studied steady-state free convection heat transfer behavior of nanofluids numerically inside a right-angle triangular enclosure filled with a porous medium with flush heater is placed on the left vertical wall. It is found that the maximum value of average Nusselt number is obtained by decreasing the enclosure aspect ratio and lowering the heater position with the highest value of Rayleigh number and the largest size of heater. It is further observed that the heat transfer in the cavity is improved with the increasing of solid volume fraction parameter of nano fluids at low Rayleigh number, but opposite effects appear when the Rayleigh number is high.

Varol, Oztop and Pop[8] solved the problem of steady, laminar, natural convection flow in a porous enclosure divided by a triangular massive partition numerically . Flow patterns and temperature distributions were presented at different aspect ratios and Rayleigh numbers .The results were found that both the Rayleigh number and aspect ratio are responsible for the unicellular flow pattern in counterclockwise direction in the enclosure. The geometric aspect ratio of the triangular portion of the cavity seriously affects the flow and heat transfer in the cavity.

Varol et al [9] studied numerically the phenomena of natural convection in an inclined square enclosure heated via corner heater. It is observed that heat transfer is maximum or minimum depending on the inclination angle and depending on the length of the corner heaters. The effect of Prandtl number on mean Nusselt number is more significant for $\operatorname{Pr}<1$.

Basak et al [10]carried out a penalty finite element analysis with bi-quadratic elements is to investigate the effects of uniform and non-uniform heating of inclined walls on natural convection flows within a isosceles triangular enclosure. The study has been found that at small Prandtl numbers, geometry does not have much influence on flow structure while at $\operatorname{Pr}=1000$, the stream function contours are nearly triangular showing that geometry has considerable effect on the flow pattern. In addition, it is observed that non-uniform heating produces greater heat transfer rates at the center of the walls than the uniform heating; however, average Nusselt numbers show overall lower heat transfer rates for the non-uniform heating case. Critical Rayleigh numbers for conduction dominant heat transfer cases have been obtained and for convection dominant regimes.

Oztop et al., [11] investigate the effects of fin location onto the bottom wall of a triangular enclosure filled with porous media. The effective parameters on flow and temperature fields are: Rayleigh number, location center of fin, dimensionless fin height, and dimensionless fin 
width. The obtained results indicated that the fin could be used as a control element for heat transfer and fluid flow.

Bilgen and Muftuoglu [12] studied cooling strategy in a square enclosure with ventilation ports and a discrete heat source at its optimum position. They searched the optimum heater position by maximizing the global conductance at different Rayleigh and Reynolds numbers and considered three different ventilation ports arrangements. The study found that the heater position is at off center in all cases; its optimum position is insensitive to the variation of $\mathrm{Ra}$ and Re.

Radhakrishnan and Venkateshan [13] discusse the results of an experimental and numerical study of fluid flow and heat transfer in an enclosure where multiple heaters are arranged in a staggered fashion. results of the numerical study are compared with the experimental results. The temperature distribution gives an insight into the power management among the heaters, so that the "coolest"' heater can be loaded most to maximize the total heat dissipation, for a prescribed temperature excess, for all the heaters.

Varol et al [14] studied the natural convection in solid adiabatic thin fin attached to porous right triangular enclosures numerically. Results observed that the thin fin can use as a passive control element for flow field, temperature distribution and heat transfer.

Türkoglu and Yücel [15] studied The flow and heat transfer in partially heated and partially cooled cavities. Computations were carried out to investigate the effects of the heater and cooler locations on the fluid flow and heat transfer. It was observed that for a given cooler location, the mean Nusselt number increases as the heater moves closer to the bottom wait. On the other hand, for a given heater location, the mean Nusselt number increases as the cooler moves closer to the top horizontal wall. For the problem considered, the maximum mean Nusselt number is obtained when the heater is slightly above the bottom wall and the cooler is slightly below the top horizontal wall. For all Rayleigh numbers considered, the same behavior was observed.

The main purpose of this study is to investigate the natural convection heat transfer from the heater element placed in enclosure have one inclined side. The review given above deals with partially heated side or partitions attached on wall besides another shape of enclosures as rectangular, triangular, and parallelogram, but a heater element located inside this geometrical enclosure has not been investigated yet .Various Rayleigh number, inclination angle of wall, height of heater and location of heater will be considered in this study .

\section{Physical model:}

The Physical diagram of the problem and the boundary conditions are shown in figure $(1)$. In this figure, the enclosure with bottom wall and vertical wall is considered of length, L. The rectangular heater kept at a constant hot temperature of $\left(T_{h}\right)$ width $w_{h}$ and height $Y_{h}$, location $X_{h}$. The inclined right wall kept at a constant cold temperature of $\left(T_{c}\right)$. The vertical left wall and horizontal walls all are insulated. 


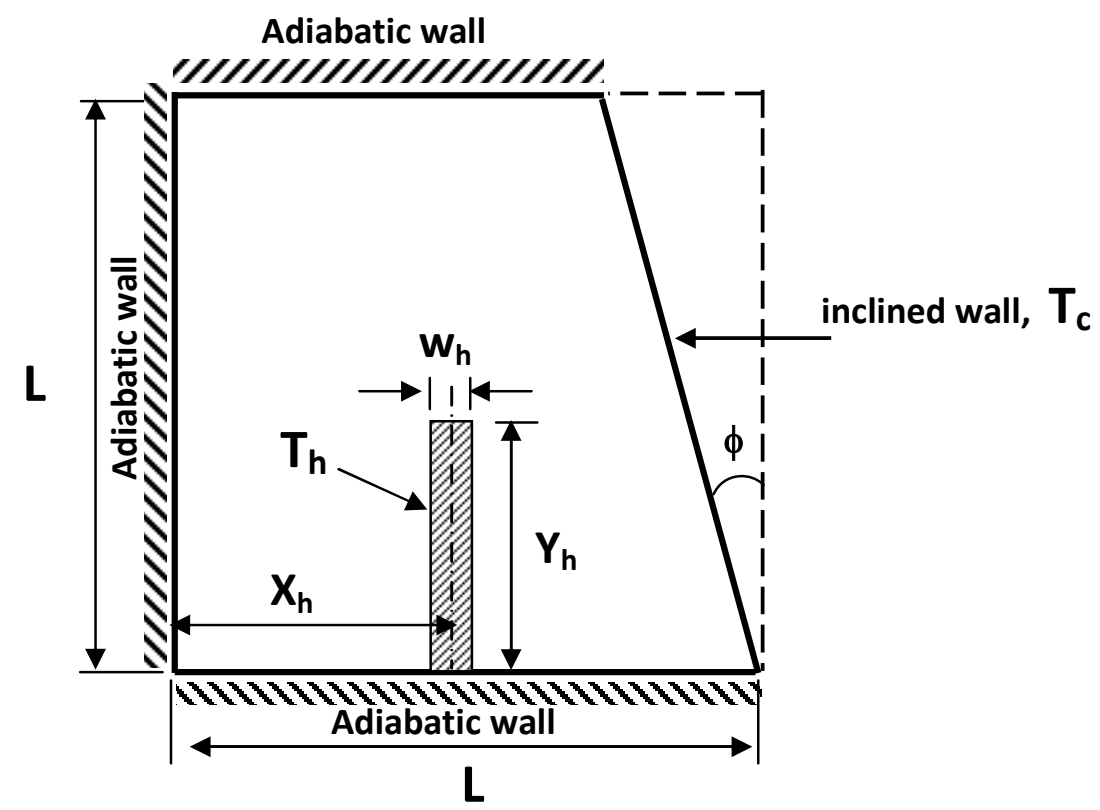

Figure (1) : Geometry of enclosure with inclined single wall

\section{Mathematical Formulation}

The system was considered to be two-dimensional, incompressible, steady state, laminar, Newtonian and with Boussinesq approximation was applied for fluid with constant physical properties and the radiation effect is negligible. The dimensionless governing equations in streamline-vorticity form can be obtained via introducing dimensionless variables as follows:

$$
\begin{aligned}
& X=\frac{x}{L}, \quad Y=\frac{y}{L}, \quad \hat{\psi}=\frac{\psi \operatorname{Pr}}{v}, \quad \Omega=\frac{\omega(L)^{2} \operatorname{Pr}}{v} \\
& \theta=\frac{T-T_{c}}{T_{h}-T_{c}}, \quad U, V=\frac{(u, v) L}{\alpha} \\
& u=\frac{\partial \psi}{\partial y}, \quad v=-\frac{\partial \psi}{\partial x}, \quad \omega=\left(\frac{\partial v}{\partial x}-\frac{\partial u}{\partial y}\right) \\
& \operatorname{Ra}=\frac{\beta g\left(T_{h}-T_{c}\right) L^{3} \operatorname{Pr}}{v^{2}}, \quad \operatorname{Pr}=\frac{v}{\alpha}
\end{aligned}
$$

Based on the dimensionless variables above governing equations (stream function, vorticity and energy equations) can be written as:

$$
\begin{aligned}
& -\Omega=\frac{\partial^{2} \psi}{\partial X^{2}}+\frac{\partial^{2} \psi}{\partial Y^{2}} \\
& \frac{\partial^{2} \Omega}{\partial X^{2}}+\frac{\partial^{2} \Omega}{\partial Y^{2}}=\frac{1}{\operatorname{Pr}}\left(\frac{\partial \hat{\psi}}{\partial Y} \frac{\partial \Omega}{\partial X}-\frac{\partial \hat{\psi}}{\partial X} \frac{\partial \Omega}{\partial Y}\right)-R a\left(\frac{\partial \theta}{\partial X}\right) \\
& \frac{\partial^{2} \theta}{\partial X^{2}}+\frac{\partial^{2} \theta}{\partial Y^{2}}=\frac{\partial \hat{\psi}}{\partial Y} \frac{\partial \theta}{\partial X}-\frac{\partial \hat{\psi}}{\partial X} \frac{\partial \theta}{\partial Y}
\end{aligned}
$$


The boundary conditions are illustrated in the physical model and they can be defined as follows:

On the inclined wall:

$\mathrm{U}=0 \quad, \quad \mathrm{~V}=0, \quad, \quad \theta=0$

On the bottom and top walls:

$\mathrm{U}=0 \quad, \quad \mathrm{~V}=0 \quad, \quad \frac{\partial \theta}{\partial y}=0$

On the left vertical wall:

$$
\mathrm{U}=0 \quad, \quad \mathrm{~V}=0 \quad, \quad \frac{\partial \theta}{\partial x}=0
$$

On the heater walls:

$\mathrm{U}=0, \mathrm{~V}=0, \quad, \theta=1$

Calculation of local Nusselt number for heater sides is performed by

$N u_{\text {left }}=-\left.\frac{\partial \theta}{\partial x}\right|_{\text {left side }}, N u_{\text {right }}=-\left.\frac{\partial \theta}{\partial x}\right|_{\text {right side }}, N u_{\text {top }}=-\left.\frac{\partial \theta}{\partial y}\right|_{\text {top side }}$

Average Nusslet numbers for sides of heaters are calculated by integration of local Nusslet number along the sides as :

$$
\begin{gathered}
N u_{\text {ave left }}=\int_{0}^{Y_{h}} N u_{\text {left }} d y \\
N u_{\text {ave right }}=\int_{0}^{Y_{h}} N u_{\text {right }} d y \\
N u_{\text {ave top }}=\int_{X_{h-}{ }^{w_{h / 2}}}^{{ }_{h+}{ }^{w_{h} / 2}} N u_{\text {top }} d x
\end{gathered}
$$

Average Nusslet number $\mathrm{Nu}$ calculated by summation all average Nusslet numbers of the sides of heater as given by:

$\mathrm{Nu}=N u_{\text {ave left }}+N u_{\text {ave right }}+N u_{\text {ave top }}$

\section{Numerical approach:}

The governing equations for steady state, laminar, two dimensional natural convection heat transfer from a heater placed on the bottom of a square enclosure are solved using finite difference method based on Taylor series. By using Cartesian mesh on the domain as shown in fig.(2), the two region mesh results, regular and irregular meshes.
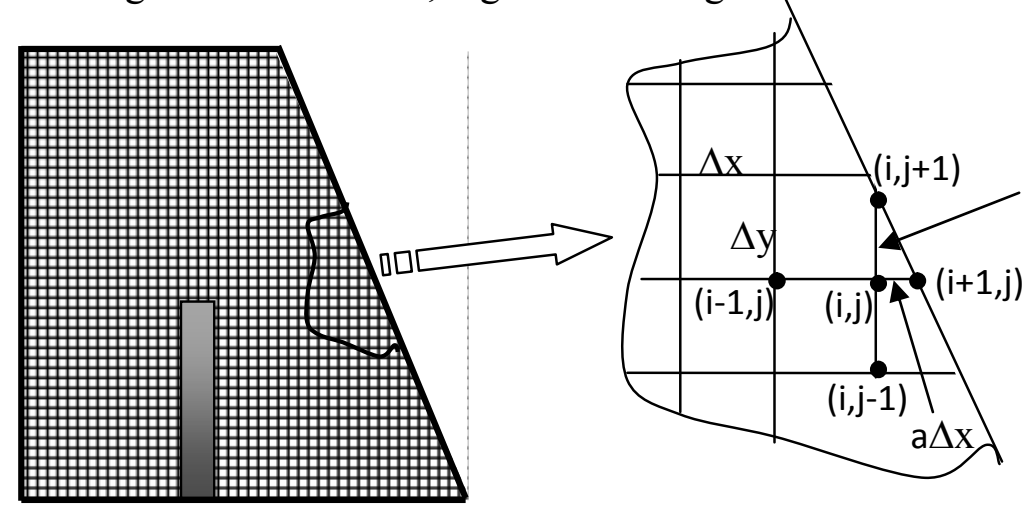

$\mathrm{b} \Delta \mathrm{y}$ 
For regular mesh, the central difference approximation for the internal nodes can be used on the interior grid points of the domain. Also the forward and backward difference approximation is used along top, bottom and left vertical walls. While the irregular mesh along the inclination right side will be generated. To apply the finite difference approximation on the grid points and for simplicity expressed for any unknown variable points $\mathrm{f}(\mathrm{x}, \mathrm{y})$, the continuous first and second order derivatives at grid point $(\mathrm{i}, \mathrm{j})$, which are $(\partial f / \partial x)_{i, j}$ and

$\left(\partial^{2} f / \partial x^{2}\right)_{i, j}$ respectively of irregular mesh may be expressed in the equations below :

$\frac{\partial f}{\partial x}=\frac{f_{i+1, j}-f_{i-1, j}}{(1+a) \Delta x} \quad, \frac{\partial f}{\partial y}=\frac{f_{i, j+1}-f_{i, j-1}}{(1+b) \Delta y}$

$\frac{\partial^{2} f}{\partial x^{2}}=\frac{2}{\Delta x(1+a)}\left(\frac{f_{i+1, j}-f_{i, j}}{a \Delta x}-\frac{f_{i, j}-f_{i-1, j}}{\Delta x}\right)$

$\frac{\partial^{2} f}{\partial y^{2}}=\frac{2}{\Delta y(1+b)}\left(\frac{f_{i, j+1}-f_{i, j}}{b \Delta y}-\frac{f_{i, j}-f_{i, j-1}}{\Delta y}\right)$

Where $\boldsymbol{a}$ and $\boldsymbol{b}$ are the coefficients multiplied by $\Delta \boldsymbol{x}$ and $\Delta y$ respectively to get the exact distances between grid point and inclined wall. The value of coefficients for all grid points can be calculated by aid the inclined angle of left side wall .The number of grid points is taken as $100 \times 100$ with uniform spaced mesh in both $\mathrm{X}$ - and Y-directions.

For the purpose of validation, the natural convection in a triangle enclosure without a heater was tested with the results of Tzeng et al.[1]. In this studies, the bottom and inclined walls are heated and cooled, respectively. The local $\mathrm{Nu}$ numbers for the test case are compared and plotted in fig.(3). The values are in good agreement with previously calculated values .

\section{Results and discussion}

The results for natural convection heat transfer from heater placed in an enclosure with adjacent inclined side wall is derived using the parameters as dimensionless height of the heater $\mathrm{Y}_{\mathrm{h}}=0.1,0.3,0.5$, dimensionless location $\mathrm{X}_{\mathrm{h}}=0.25,0.5$, inclination angle of right inclined wall $\Phi=10^{\circ}, 20^{\circ}, 30^{\circ}$, Rayligh number from $10^{3}$ to $10^{5}$. Prandtl number was taken as $\mathrm{Pr}=0.72$ and dimensionless width of the heater is constant and equal $\mathrm{w}=0.06$.

The results obtained can be presented in two sections. The first section will present temperature fields as an isotherms lines, flow fields presented on streamlines and velocity profiles. The second section will discuss heat transfer including variation of local and mean Nusselt Numbers .

\subsection{Temperature and flow fields}

Figure (4) shows the isotherms lines and streamlines at inclination angle of right wall $\Phi=30^{\circ}$, at location of heater at $X_{h}$ of 0.25 , and length of heater $Y_{h}$ of 0.3 for different Rayligh number $\mathrm{Ra}=10^{3}, 10^{4}, 10^{5}$. It is clear that the increase of Rayligh number leads to increase of vigor of natural convection as shown in temperature gradient and boundary layer along the right side of heater and the upper section of inclined cold wall. The figure also shows the streamlines as one cell rotates in clockwise (CW) direction. As a Rayligh number 
increase which causes increase in velocity rotation of fluid flow as be clear of maximum stream function value $\Psi_{\max }$ and the maximum value was at $\mathrm{Ra}=10^{5}$.

Figure (5) shows the effects of inclination angle of right cold wall on temperature and flow fields at Ra of $10^{5}$, location heater $\mathrm{X}_{\mathrm{h}}$ of 0.5 and length of heater $\mathrm{Y}_{\mathrm{h}}$ of 0.5 for different inclination angles $\Phi=10^{\circ}, 20^{\circ}, 30^{\circ}$. As increase of inclination angle causes more activity of natural convection as shown of temperature gradient along the heater and cold inclined wall due to convergence between the hot and cold surfaces because the inclination . Furthermore, what may be observed that the fluid exchange varies multi-cellular flow as inclination angle increased .

Figure (6) shows the effect of length of heater on the flow and temperature fields at $\mathrm{Ra}=10^{5}$, inclination angle $\Phi=20^{\circ}$ and location of heater $\mathrm{X}_{\mathrm{h}}$ of 0.25 for different heater lengths $\left(\mathrm{Y}_{\mathrm{h}}=0.1,0.3,0.5\right)$. It can be observed that increasing the length of heater leads to increasing in heated area of heater which causes increase of temperature gradient region. In the flow field as shown in figure increasing of heater length's will be protracted the cell of flow and extend the multi-cellular flow, in other words more efficient of natural convection.

Figure (7) shows the effect of heater location at $\mathrm{Ra}=10^{4}, \Phi=30^{\circ}, \mathrm{Y}_{\mathrm{h}}=0.5$ for $\mathrm{X}_{\mathrm{h}}=0.25$ and $X_{h}=0.25$. It can be observed that placing the heater approaches to the inclined cold wall $\left(X_{h}=0.5\right)$ causes more heat transfer and increase the temperature gradient along the heater and inclined wall and the flow approach to the multi-cellular flow .

Horizontal and vertical velocities profiles are presented in figure (8) at $\mathrm{Ra}=10^{5}$, $\Phi=10^{\circ}, Y_{h}=0.5$ and $X_{h}=0.5$. Horizontal velocity profiles are plotted at three different locations in $\mathrm{x}$-direction as $\mathrm{x}=0.25, \mathrm{x}=0.5$ and $\mathrm{x}=0.75$. Also the vertical velocities are plotted at three different locations in $y$-direction as $y=0.25, y=0.5$ and $y=0.75$. Figure (8a) shows the maximum negative value of horizontal component velocity is at tip of heater $(x=0.5, y=0.5)$, while the maximum positive value is at upper surface because the fluid exchanges its direction. The minimum value of horizontal velocity becomes zero at $y=0.72$ at center of the core of the cell. The velocity profile $(x=0.25)$ for the same case, the value of the horizontal velocity beginning at zero value and then increases at $y=0.4$ but the maximum value doesn't locate at the lower surface because the fluid motion at this region becomes slow or approach to stagnation region. Finally reaches at maximum value at upper surface, the minimum value is zero at $\mathrm{y}=0.68$ in the other word where approach the core of the flow cell. The component at $(\mathrm{x}=0.75)$ is similar to the behavior of $(\mathrm{x}=0.25)$ but maximum value locate at the lower surface at the boundary layer and the zero value is at (from $y=0.3$ to $y=0.5$ ) because this section is at core of flow cell.

Figure $(8 b)$ observed the vertical velocity $(y=0.25)$ it is, generally very small because it located at left region of enclosure and the maximum value at $\mathrm{x}=0.53$, in other words along the right side of heater and its near value at $\mathrm{x}=0.95$ nearest the inclined wall but in opposite direction . At the velocity profile $(\mathrm{y}=0.5)$ have two maximum values but opposite directions at the left and right tips of heaters. At velocity $(y=0.75)$ the maximum values are at left vertical and inclined walls.

In figure (9) similar behavior but location of heater at $X_{h}=0.25$, the maximum values of horizontal and vertical velocities are less than presented in figure (8) 
Figure (10) shows the direction of the horizontal velocities at profiles $(x=0.25)$ and $(\mathrm{x}=0.75)$ are opposite that presented previously because the multi-cellular flow that causes exchanging the velocity direction. Figure (5.c) confirms this fact. The same matter gets in the vertical velocity as shown in figure (10.b).

\subsection{Heat transfer}

Variation of average Nusselt number with Rayligh number for different heater lengths , locations and inclination angles of inclined cold wall are presented in figure (11. a,b,c) . All figures show that increasing in Rayligh number with all different parameters cause increasing average Nusselt number. Also increase the length of heater leads to increase the average Nusselt number. The increasing difference in average Nusselt number between heater length ( 0.1 to 0.3$)$ is larger than increasing difference between $(0.3$ to 0.5$)$

The maximum increasing ratio of average Nusselt number obtained at $\mathrm{Ra}=10^{5}$, $\mathrm{X}_{\mathrm{h}}=0.5$ and $\Phi=30^{\circ}$ is approximately $(60 \%)$ at increasing length of heater from 0.1 to 0.5 . Also The maximum increasing ratio of average Nusselt number is approximately ( $49 \%$ at increasing length of heater from 0.1 to 0.3 and the maximum increasing ratio of average Nusselt number is approximately ( $20 \%$ ) at increasing length of heater from 0.3 to 0.5 .

Also the figure shows increasing average Nusselt number where the heater becomes near the inclined wall at $\mathrm{X}_{\mathrm{h}}=0.5$ because the distance between the hot and cold walls is short . And the maximum increasing ratio is $(41 \%)$ at $\mathrm{Ra}=10^{3}, \mathrm{Y}_{\mathrm{h}}=0.5$ and $\Phi=30^{\circ}$.

Figure (12) shows the variation of average Nusselt number with Rayligh number for different inclination angle of cold wall .It can be observed that increasing Nusselt number as increasing of inclination angle.

The effect of both heater length and its location at inclination angle of $\Phi=20^{\circ}$ is presented in figure (13). The maximum value of Nusselt number is at $X_{h}=0.5$ and $Y_{h}=0.5$ for different Raligh numbers while the minimum value of Nusselt number is at $X_{h}=0.25$ and $\mathrm{Y}_{\mathrm{h}}=0.1$ for different Raligh numbers.

Variation of local Nusselt number along the heater walls, left and right sides at inclination angle $\Phi=30^{\circ}, X_{h}=0.25, Y_{h}=0.5$ at two Rayligh numbers $\mathrm{Ra}=10^{4}$ and $\mathrm{Ra}=10^{5}$ are presented in figure (14). It can be seen on the right side of heater, the local Nusselt number at the bottom of heater is great value and then decrease gradually along the heater length to reach the minimum value at $y=0.42$. Then increase to the maximum value at the tip of heater. While the local Nusselt number at left side is less than that at the right side, because the right side of heater faces are the cold inclined wall and the motion of fluid along the right side is more efficient. However, along the left side the motion of fluid is small approach to the stagnation region because of insulated intersection walls (lower left corner).

Figure (15) shows the variation of local Nusselt number along the top side of heater (tip) at $\Phi=30^{\circ}, X_{h}=0.25, Y_{h}=0.5$. The maximum value of local Nusselt number is at right corner of heater.

Figure (16) shows the variation of average Nusselt number on the right, left, top and overall average Nusselt number with Rayligh number at $\Phi=20^{\circ}, X_{h}=0.25, Y_{h}=0.3$. As given in 
No. 2

April 2015

the figure, $\mathrm{Nu}_{\text {ave left }}$ is almost of small value and constant approaching to the conduction for all Raylgh numbers . The $\mathrm{Nu}_{\text {ave top }}$ is larger than $\mathrm{Nu}_{\text {ave left }}$ with small value. While the maximum value of average Nusselt number is at along the right side of heater $\left(\mathrm{Nu}_{\text {ave }}\right.$ right $)$ for all Rayligh numbers and the increasing ratio is significant .The overall average Nusselt number is similar to the $\mathrm{Nu}_{\text {ave }}$ right in behavior but is larger than it .

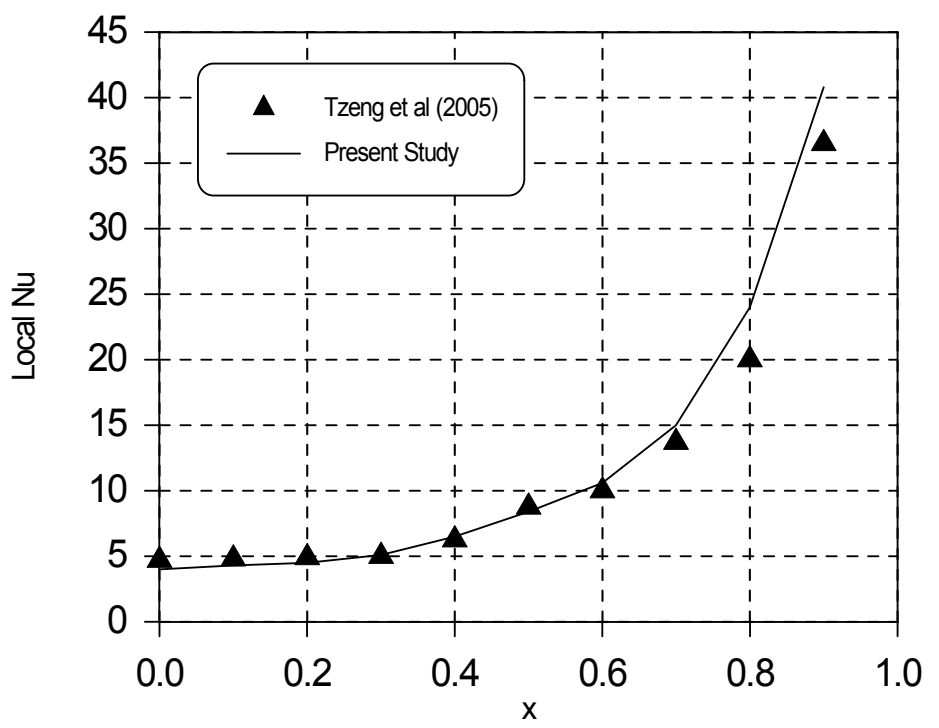

Figure: (3) Comparison of local Nusselt number with literature
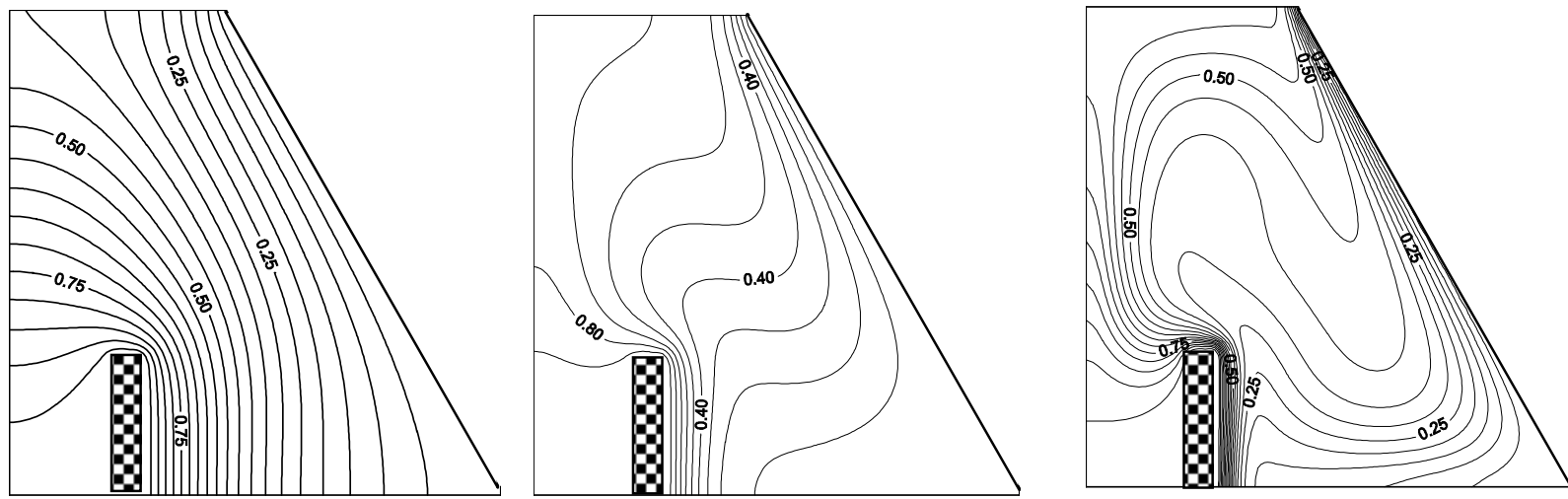

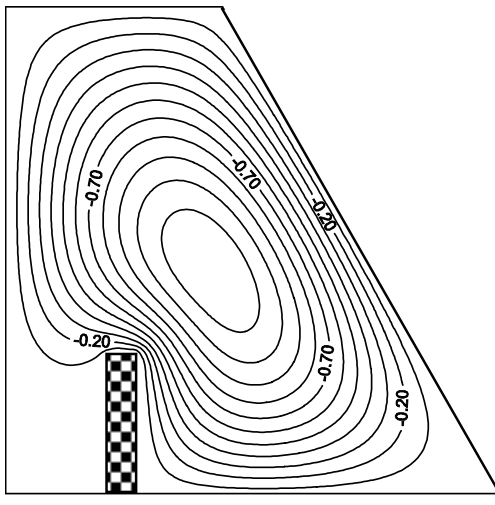

(a)

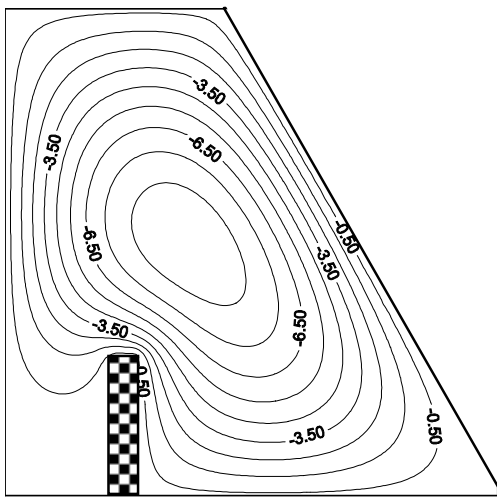

(b)

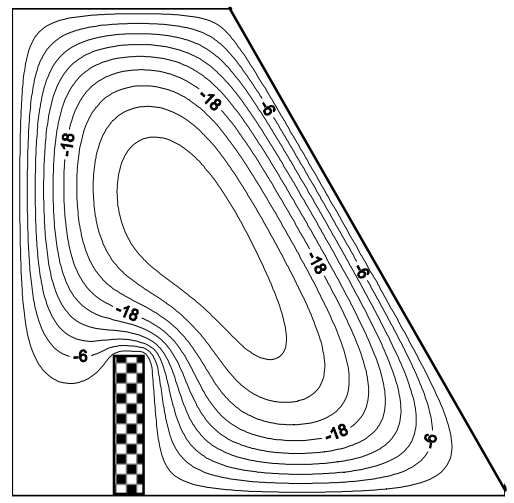

(c)

Figure: (4) Isotherms lines \& stream functions for $\Phi=30^{\circ}, X_{h}=0.25, Y_{h}=0.3$ a) $R a=10^{3}$, b) $\left.R a=10^{4}, c\right) R a=10^{5}$ 

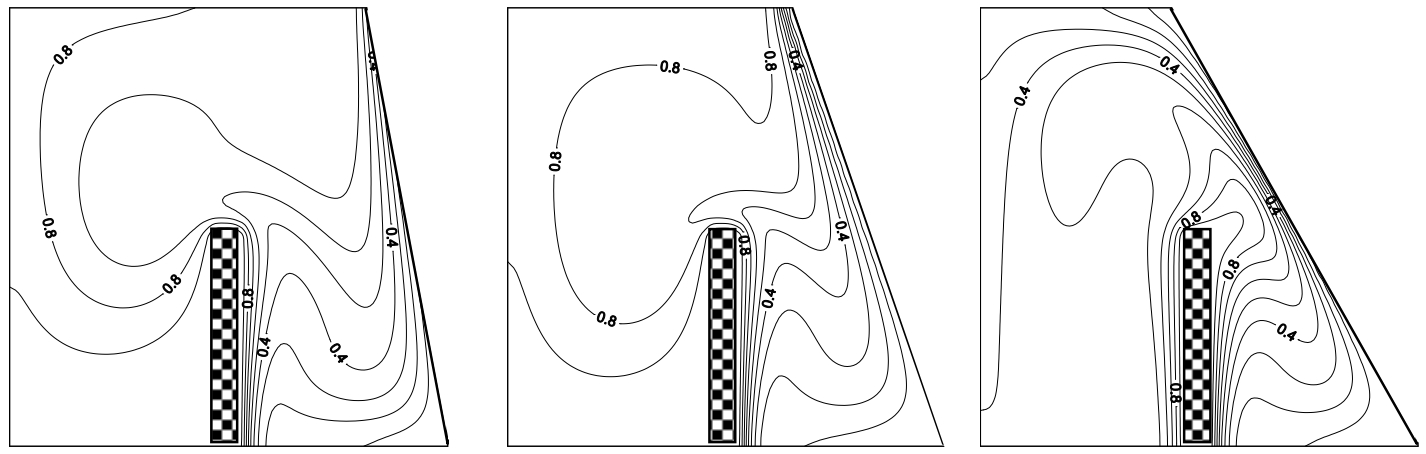

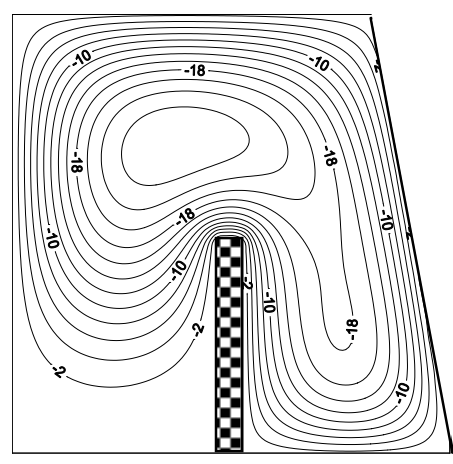

( a )

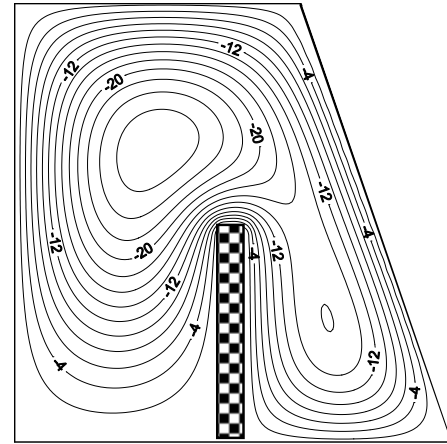

(b)

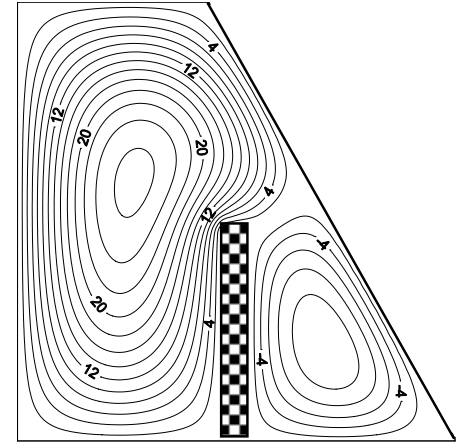

(c)

Figure (5): Isotherms lines \& stream functions for $X_{h}=0.5, Y_{h}=0.5$, Ra=10 $\left.\left.\left.a\right) \Phi=10^{\circ}, b\right) \Phi=20^{\circ}, c\right)$ $\Phi=30^{\circ}$
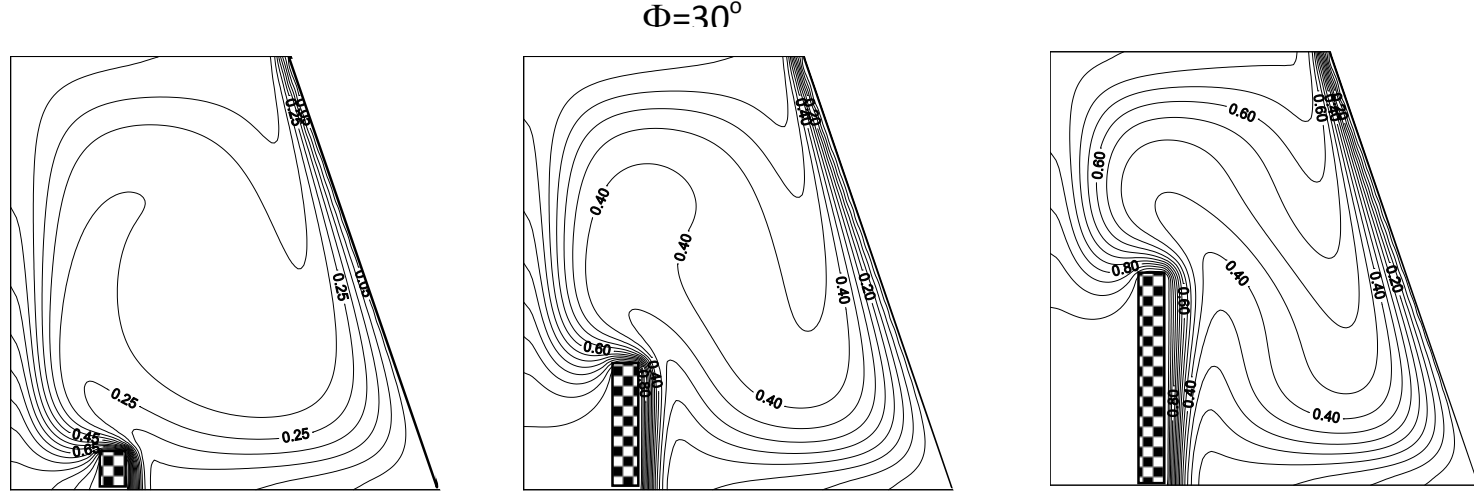

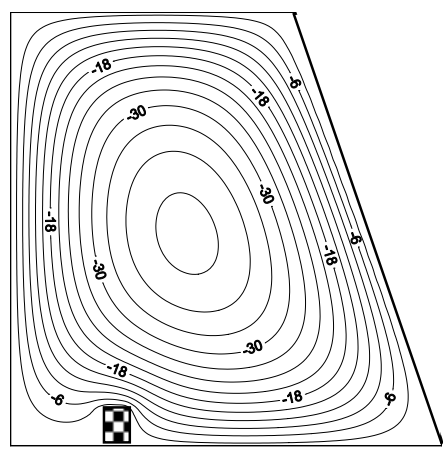

(a)

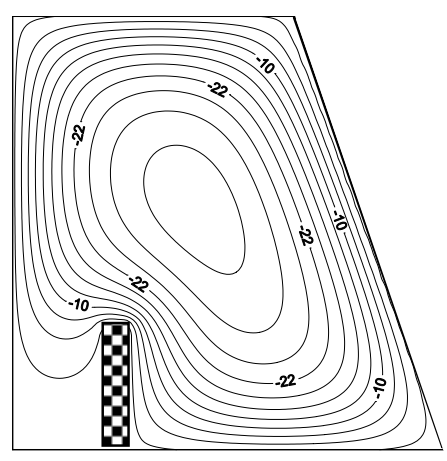

(b)

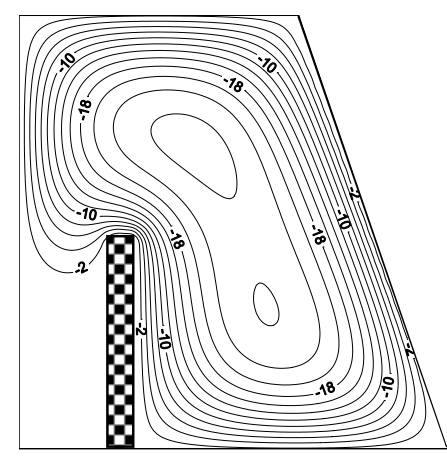

(c)

Figure (6): Isotherms lines \& stream functions for $X_{h}=0.25, \Phi=20^{\circ}, R a=10^{5}$ a) $Y_{h}=0.1$, b) $Y_{h}=0.3$ 
No. 2
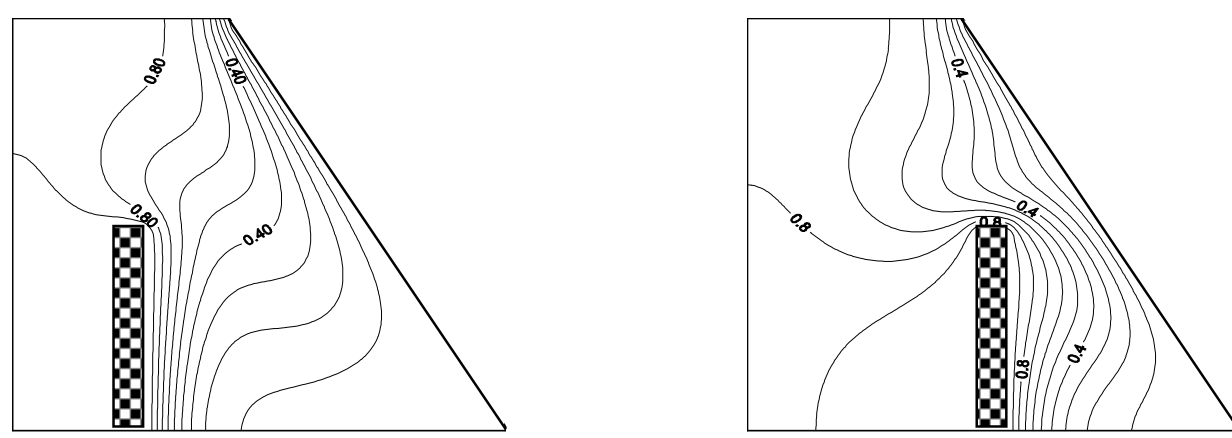

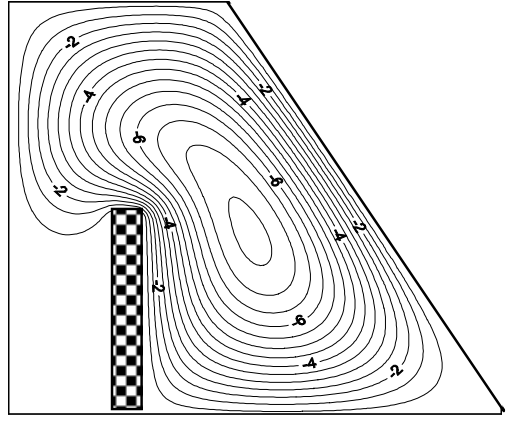

( a )

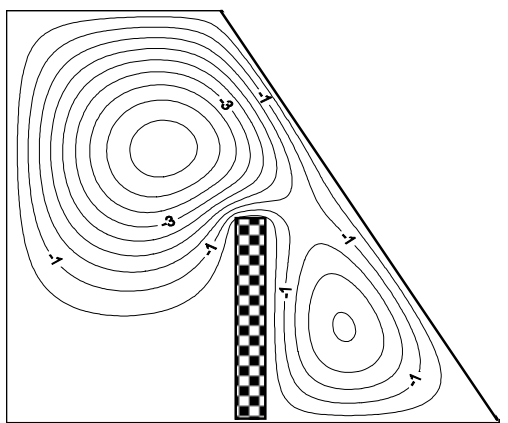

(b)

Figure (7): Isotherms lines \& stream functions for $Y_{h}=0.5, \Phi=30^{\circ}, R a=10^{4}$ a) $X_{h}=0.25$, b) $X_{h}=0.5$

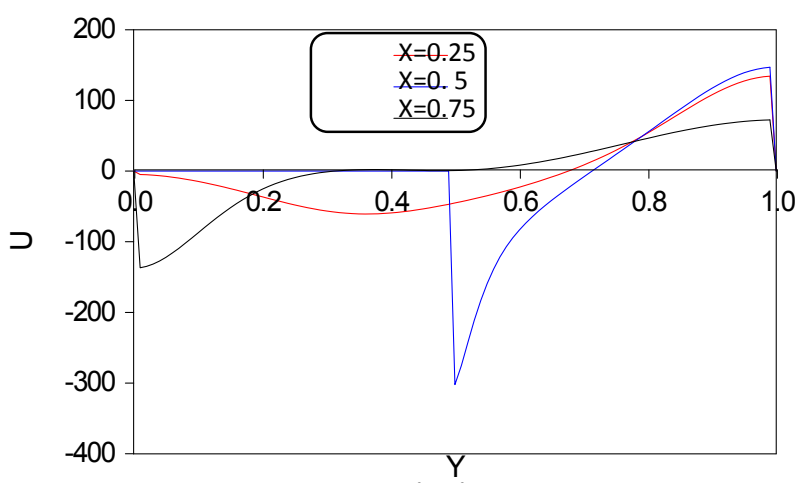

( a )

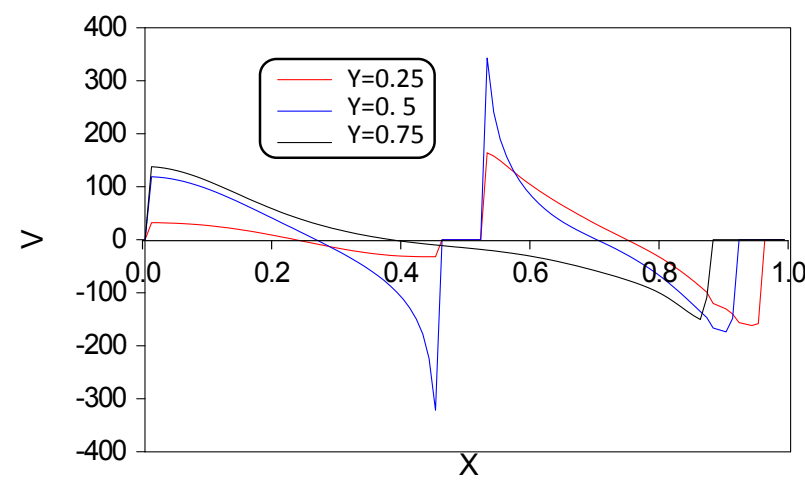

(b)

Fig (8) : Velocity profiles at $R a=10^{5} \Phi=10^{\circ}, X_{h}=0.5, Y_{h}=0.5$ a)horizontal velocity b) vertical velocity

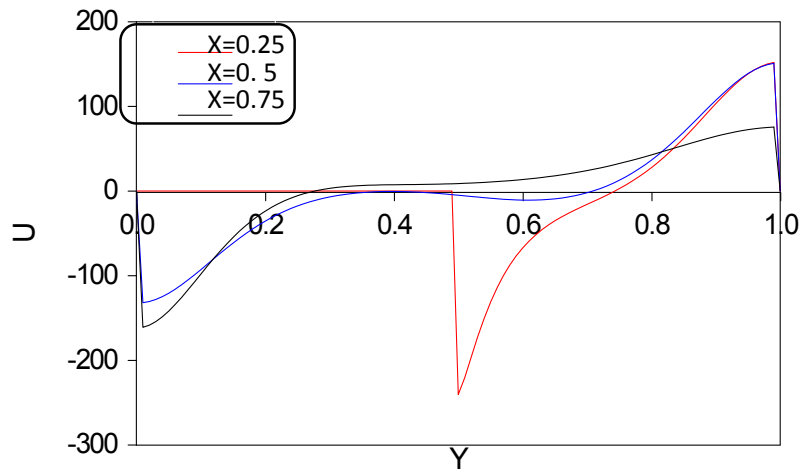

( a )

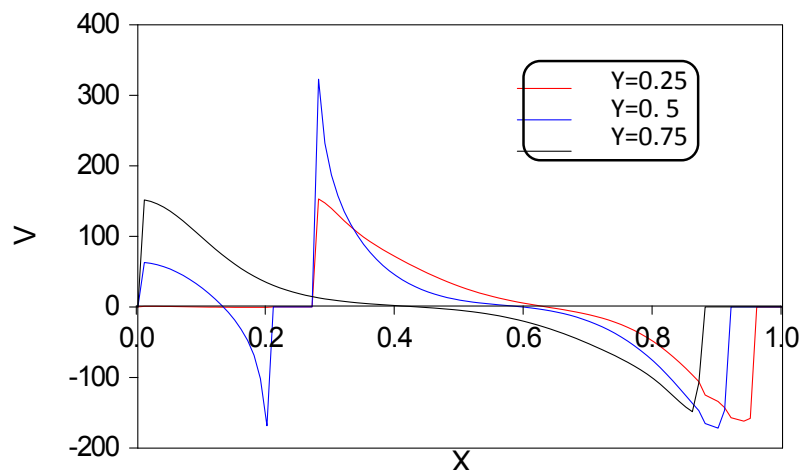

(b)

Fig (9) : Velocity profiles at $R a=10^{5} \Phi=10^{\circ}, X_{h}=0.25, Y_{h}=0.5$ a)horizontal velocity b) vertical velocity 


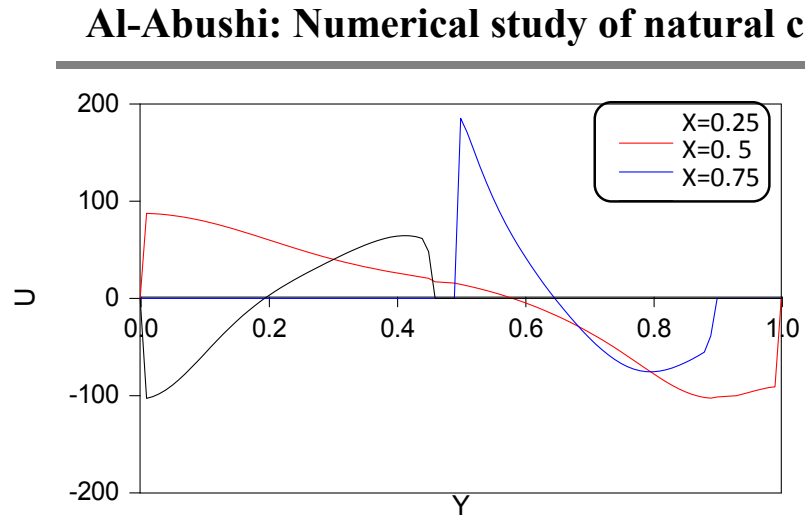

(a)

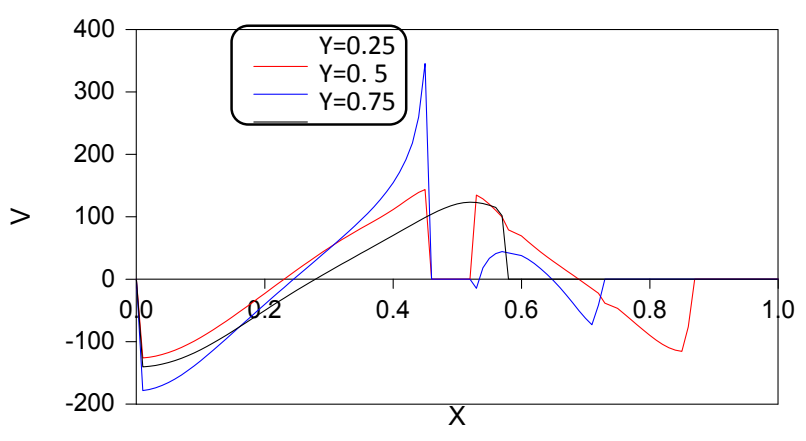

(b)

Fig (10) : Velocity profiles at $R a=10^{5} \Phi=30^{\circ}, X_{h}=0.5, Y_{h}=0.5$ a)horizontal velocity b) vertical velocity
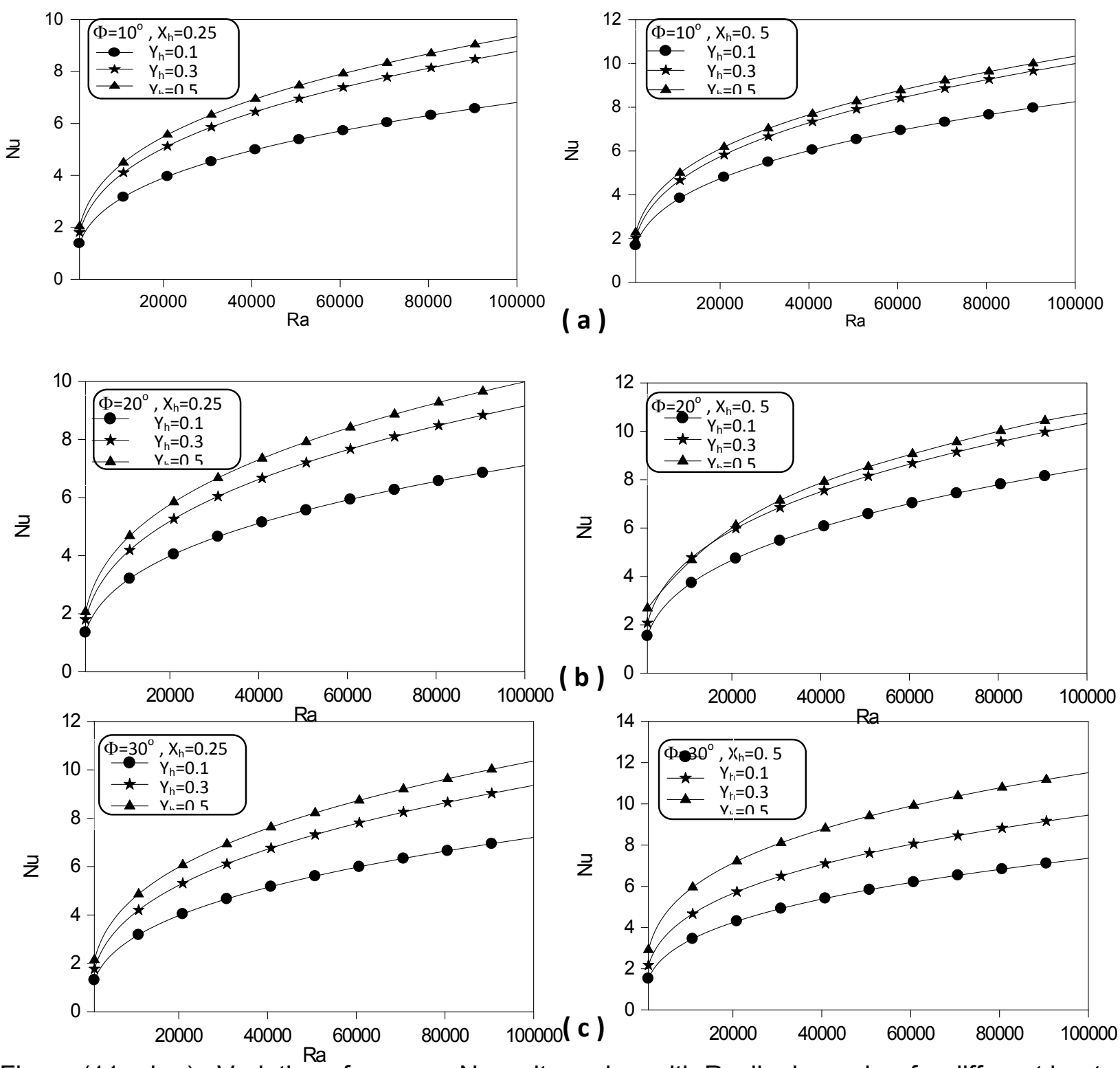

Figure $(11, a-b-c)$ : Variation of average Nusselt number with Rayliegh number for different heater length, different location and different inclination of cold wall 


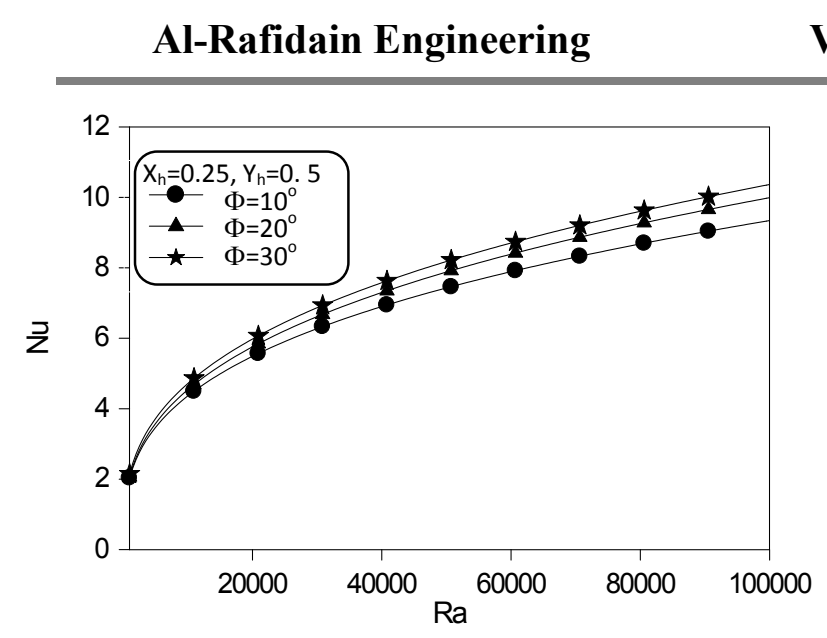

Figure (12) Variation of average Nusselt number with Ra for different $\Phi$

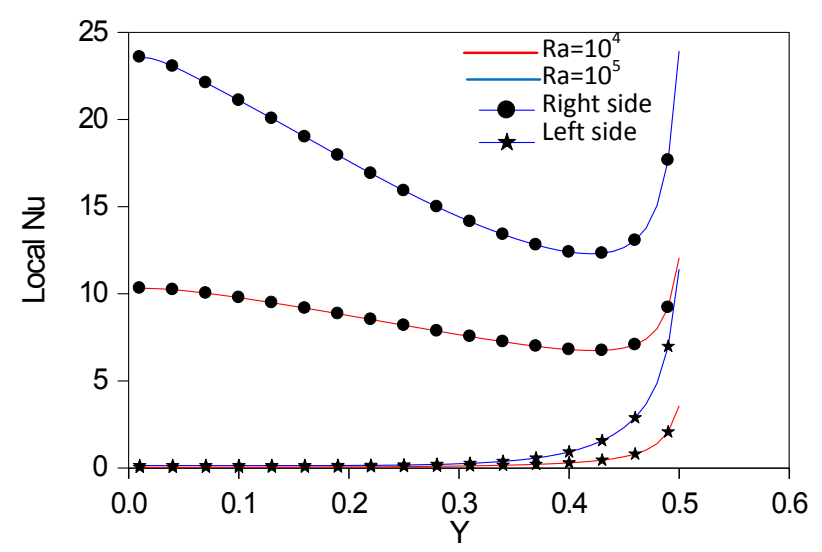

Fig. (14) : Variation of local $\mathrm{Nu}$ along the heater wall, left and right side $\Phi=30^{\circ}, X_{h}=0.25, Y_{h}=0.5$
Vol.23

No. 2

April 2015

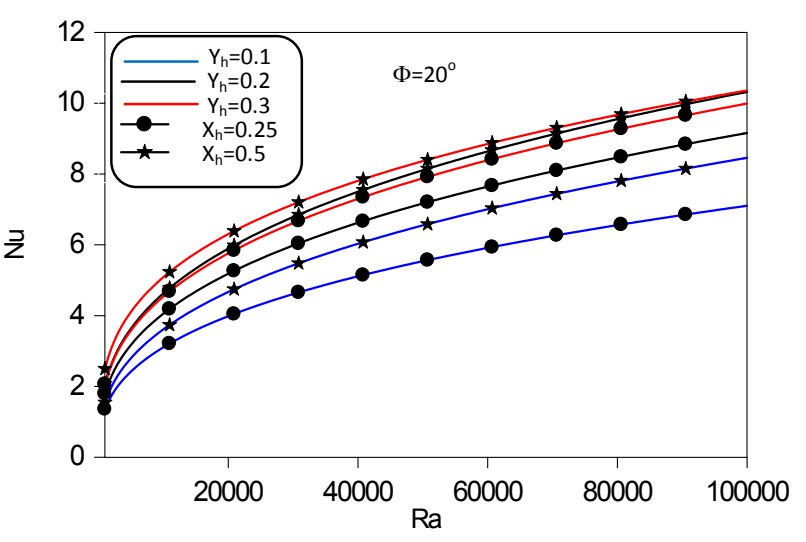

Figure (13) Variation of average Nusselt number with Ra for different $Y_{h}$ and location of heater at

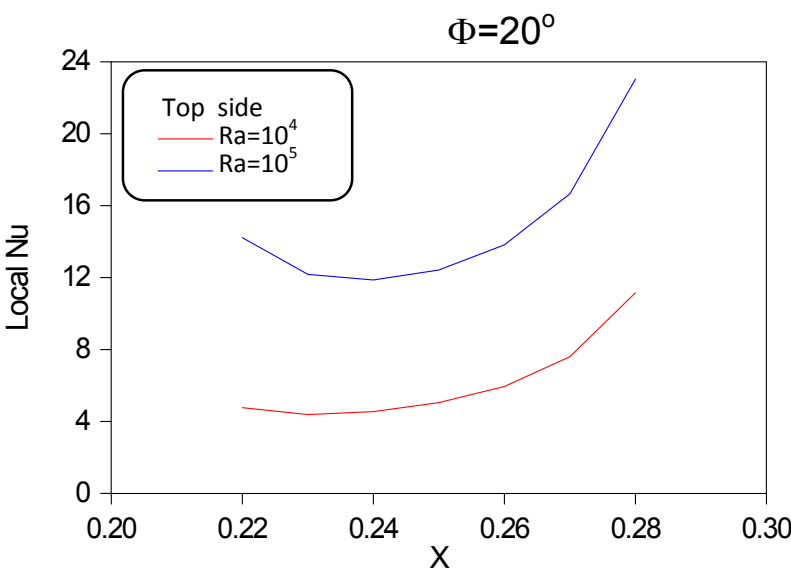

Fig. (15) : Variation of local Nu along the top side of heater $\Phi=30^{\circ}, X_{h}=0.25, Y_{h}=0.5$

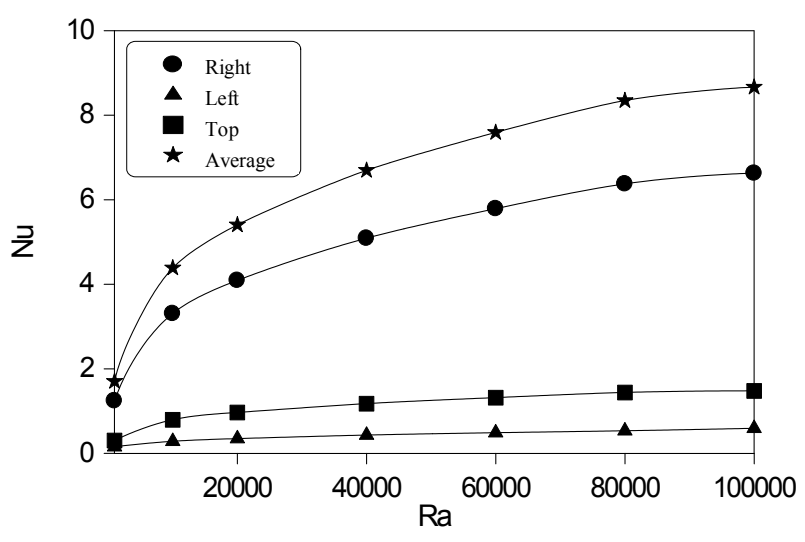

Fig. (16) : Variation of average $\mathrm{Nu}\left(\mathrm{Nu}_{\text {ave left }} \mathrm{Nu}_{\text {ave right }}, \mathrm{Nu}_{\text {ave top }}, \mathrm{Nu}\right)$ with $\mathrm{Ra}$ $\Phi=20^{\circ}, X_{h}=0.25, Y_{h}=0.3$

\section{Conclusions :}

This study investigated numerically the characteristics of natural convection heat transfer from heater placed on the bottom of a square enclosure with one inclined wall which has a constant low temperature . A detailed analysis of the distribution of streamlines, 
isotherms and Nusselt number carried out to investigate the effect of the locations and length of the heater on the fluid flow and heat transfer in the square enclosure for different Rayleigh numbers and different inclination angle. These results indicated many conclusions :

1-The average Nusselt number increases with increasing the Rayliegh number in all cases.

2-The average Nusselt number increases with increasing the heater length and The maximum increasing ratio of average Nusselt number obtained at $\mathrm{Ra}=10^{5}, \mathrm{X}_{\mathrm{h}}=0.5$ and $\Phi=30^{\circ}$ is approximately $(60 \%)$ at increasing length of heater from 0.1 to 0.5 .

3- The average Nusselt number increases with increasing the location of heater, and the maximum increasing ratio is $(41 \%)$ at $\mathrm{Ra}=10^{3}, \mathrm{X}_{\mathrm{h}}=0.5, \mathrm{Y}_{\mathrm{h}}=0.5$.

4- The average Nusselt number increases with increasing the inclination angle of cold wall as depending on Rayligh number .

5-The local Nusselt number at the right side of heater is larger than that at the top and left sides of it.

6-The multi-cellular flow appears or grows where inclination angle of inclined wall increased or heater approach to the inclined wall at high Rayligh numbers .

\section{References}

[1] S.C. Tzeng, J.H. Liou, R.Y. Jou, Numerical simulation-aided parametric analysis of natural convection in a roof of triangular enclosures, Heat Transfer Engrg. 26 (2005) 6979.

[2] A.C. Baytas, I. Pop, Free convection in oblique enclosures filled with a porous medium, Int. J. Heat Mass Transfer 42 (1999) 1047-1057.

[3] F. Moukalled, S. Acharya, Natural convection in a trapezoidal enclosure with offset baffles, J. Them. Heat Transfer 15 (2001) 212-218.

[4] Y. Varol, H.F. Oztop, Free convection in a shallow wavy enclosure, Int. Comm. Heat Mass Transfer 33 (2006) 764-771.

[5] Y. Varol , H.F. Oztop , I. Pop , Numerical analysis of natural convection in an inclined trapezoidal enclosure filled with a porous medium, Int. J. Thermal Sciences 47 (2008) 1316-1331.

[6] T. Basak , S. Roy , A. Singh , B.D. Pandey, Natural convection flow simulation for various angles in a trapezoidal enclosure with linearly heated side wall(s), International Journal of Heat and Mass Transfer 52 (2009) 4413-4425

[7] Q. Sun, I. Pop , Free convection in a triangle cavity filled with a porous medium saturated with nano- fluids with flush mounted heater on the wall, Int. J. Thermal Sciences 50 (2011) 2141-2153

[8] Y. Varol , H. F. Oztop , I. Pop , Natural convection flow in porous enclosures with heatingand cooling on adjacent walls and divided by a triangular massive partition, Int. Comm. Heat and Mass Transfer 35 (2008) 476- 491

[9] Y. Varol , H. F. Oztop , A. Koca , F. Ozgen, Natural convection and fluid flow in inclined enclosure with a corner heater, Applied Thermal Engineering 29 (2009) 340-350.

[10] T. Basak , S. Roy , S. K. Babu , A.R. Balakrishnan, Finite element analysis of natural convection flow in a isosceles triangular enclosure due to uniform and non-uniform heating at the side walls, Int. J. Heat and Mass Transfer 51 (2008) 4496-4505.

[11] Y. Varol , H. F. Oztop , A. Varol, Natural convection in porous triangular enclosures with a solid adiabatic fin attached to the horizontal wall, Int. Comm. Heat and Mass Transfer 34 (2007) 19-27. 
[12] E. Bilgen, A. Muftuoglu, Cooling strategy by mixed convection of a discrete heater at its optimum position in a square cavity with ventilation ports, Int. Comm. Heat and Mass Transfer 35 (2008) 545-550 .

[13] T.V. Radhakrishnan, C. Balaji , S.P. Venkateshan, Optimization of multiple heaters in a vented enclosure - A combined numerical and experimental study, Int. J. Thermal Sciences 49 (2010) 721-732.

[14] Y. Varol , H. F. Oztop , A. Varol , Effects of thin fin on natural convection in porous triangular enclosures , Int. J. Thermal Sciences 46 (2007) 1033-1045.

[15] S.c.Chapra, and R.P. Canale, Numerical Methods for Engineering, McGrewHill,NewYork2002.

12. G. J. Borse, FORTRAN77 and Numerical Method for Engineering, McGraw- Hill Book Company, Inc., 1985. 